\title{
Factors Affecting 72-Hour Unplanned Return Visits after Emergency Department Index Discharge of a Tertiary Private Hospital in the Philippines
}

\author{
Ma. Lourdes Concepcion D. Jimenez, ${ }^{1,2}$ Rafael L. Manzanera, ${ }^{3}$ Ronne D. Abeleda, ${ }^{2}$ Diego A. Moya, ${ }^{3}$ \\ Jose V. Segura, ${ }^{4}$ Mark B. Carascal ${ }^{2}$ and Jose J. Mira ${ }^{5,6}$ \\ ${ }^{1}$ Ateneo School of Medicine and Public Health, Philippines \\ ${ }^{2}$ The Medical City, Ortigas, Philippines \\ ${ }^{3}$ Health and Economic Benefits Area, MC Mutual, Barcelona, Spain \\ ${ }^{4}$ Operational Research Center, Universidad Miguel Hernández, Elche, Spain \\ ${ }^{5}$ Health Psychology Department, Universidad Miguel Hernández, Elche, Spain \\ ${ }^{6}$ Alicante-Sant Joan Health District, Alicante, Spain
}

\begin{abstract}
Objectives. This study aimed to analyze if the indicator 72-hours Unplanned Return Visits after Emergency Department (ED) index discharge was influenced by the patient's age, triage severity, month, payment methods, and length of stay. Likewise, it aimed to determine if the 72-hour Unplanned Return Visits was a robust indicator in assessing the quality of Emergency Department services.
\end{abstract}

Methods. This was a retrospective single-center study from January to December 2017. Data were retrieved from a tertiary hospital in the Philippines. All Emergency Department patients discharged on their index visit were monitored for Unplanned Return Visits within 72 hours in the hospital. A univariate and multivariate logistic regression model was used to assess the variables associated with the 72-hour Unplanned Return Visits.

Results. The 72-hour Unplanned Return Visits rate was measured at 2.67\%, with the highest occurrence on the first 24 hours, and with predominance on third-party payer ( $p .<.0001)$, pediatrics (.$<0001)$, January $(p<.0001)$, February $(p<.0001)$, November $(p<.0001)$, December $(p<0001)$, and shorter length of stay $(p<.0001)$ discharged after ED index visit.

Conclusions. Strong association of Unplanned Return Visits during the first 72 hours after Emergency Department index discharge was found for patients financed through third party-payers, with seasonal variations and inclination to the younger population with shorter length of stay. These findings warrant exploratory studies to determine the reasons for the 72-hour Unplanned Return Visits after Emergency Department index discharge and investigation on the association of premature discharge, socio-economic, health structure, and illness progression.

Key Words: emergency department, length of stay, triage, unscheduled return visits

\section{INTRODUCTION}

Corresponding author: Ma. Lourdes Concepcion D. Jimenez, MD The Medical City

Ortigas Avenue, Pasig City, Philippines

Email: Idjimenez@themedicalcity.com
The conventional perception by which the Emergency Department (ED) has been operating was based on its ability to cater to the most, if not all, of the population who seeks consultation thereby making efficiency as the cornerstone of ED practice that is often translated as a measurement of Length of Stay (LOS). This works on the premise that regulating the time spent at the $\mathrm{ED}$ will somehow address the volume of patients, clinical outcomes, and patient satisfaction.

This study focuses on Unplanned Return Visits (URVs) after EDs index discharge within 72 hours, a globally used quality indicator. The implications of URVs can both 
affect safety and efficiency, leading to overcrowding and morbidity. Literature supports the underlying explanation for URV san be associated with a premature release from the first visit, missed diagnosis or treatment failure. ${ }^{1-2}$ Some studies categorized the underlying cause of URVs as either patient-related, illness-related or system-related factors. ${ }^{3-4}$ This indicator has been popularly used worldwide, which led to the global utilization of an acceptable standard reference within the range of 1-5\%. ${ }^{5}$ It was further explained that obtaining values below the range $(<1 \%)$ can reflect an excessive risk of aversion and beyond the scope $(>5 \%)$ indicates poor quality of care. ${ }^{6}$ Also, studies emphasized the implication of URVs such as unnecessary workload, overcrowding, and increased expenditures. ${ }^{7-8}$

However, recent study questions the appropriateness of URVs in the evaluation of the quality of care provided.9-11 In this regard, doubts were raised in the utilization of URV as a quality indicator since it can be influenced by certain factors such as seasonal variations, the severity of cases and factors such as equity and age of patients, to be validated in adult and pediatric patients.

The contradictory interplay balancing the increasing ED demands and adhering with the efficiency, the 24/7 ED accessibility for all specialty regardless of severity levels, and the payment agreement between third-party payer and the Hospital has led ED in extending its services by acting as a substitute to primary care on its' absence and has responded to the convenience of patients.

The objective of this study was to analyze if the indicator 72-hours URVs after ED index discharge was influenced by age, triage severity, time of the year, payment methods, and Length of Stay (LOS). Likewise, we aimed to determine if the 72-hour URV was a robust indicator to assess the quality of ED services.

\section{METHODS}

This was a retrospective descriptive study that utilized the emergency database of the adult and pediatric section in the ED of a private tertiary hospital located in an urbanized area in the Philippines for one year from the period of January to December 2017. The local Institutional Review Board approved this study with a registry number of GCS-ER-2017-105.

The Philippines, having a dual health care delivery, has a total health expenditure of $4.7 \%$ of GDP (34\% public vs. $66 \%$ private one), of which around $50 \%$ are financed through Out of Pocket (OOP) payment schemes. ${ }^{12}$ Health services in the public sector are provided by health facilities under the National Government funded through a tax-based budgeting system. The private sector is mainly marketoriented and generally paid through OOP or third party payer that can be subsidized through the Philippine Health Insurance Corporation (PhilHealth) for public and private sectors with an average ceiling of $30 \%$ of the expenditures. ${ }^{12}$
This hospital operates $24 / 7$, providing adult and pediatric services led by an overall head and section coordinators with a total of 58 contractual consultants serving a 12-hour duty at 2-3 per week and 150 employed nurses and allied services with a 40-hour duty per week.

For this study, the following variables were identified: (a) demographics (i.e., age and gender); (b) payment schemes \{i.e. OOP and third-party payer (i.e. Health Maintenance Organization)\}; (c) triage category; (d) month of consultation; (e) Length of stay; and (f) Unplanned Return Visits rate within 72 hour. Currently, these are the only identified variables automatically retrieved from the system information.

The hospital has two payment schemes for the ED consultations wherein the majority (70\%) are financed through third-party payers covering a portion of the payment by insurance and employers that includes Health Maintenance Organization (HMOs). In contrast, others are funded from OOP, wherein the cost is paid by the patient.

The hospital follows an institutional three-tier triage level based on the modified Canadian Triage Scale (CTAS) for adults and pediatrics categorized as (a) Emergent: patients with life-threatening cases requiring immediate and rapid management, (b) Urgent: patients with significant medical problems that could become life threatening, (c) Non-urgent: patients with stable conditions.

Data collection was possible with the use of a wireless tracking device known as Radio Frequency Identification (RFID), which operates through an electromagnetic field to transfer data. The completed consultation data was extracted from the RFID and subsequently sorted alphabetically by the patient's name and successively per date and time of visit. Afterward, the data was generated by applying a formula to get the duration from the last date and time of the index visit until the start of the date and time of the next visit.

The continuous variables were presented as means and standard deviations, while the categorical variables were expressed as counts and percentages. To evaluate the univariate statistical significance, a t-test for independent samples (continuous variables) or a Chi-square test (categorical variables) was performed. To adjust the multivariate logistic regression model, we randomly selected $2 / 3$ of the sample (derivation sample). The remaining $1 / 3$ of the sample was used to validate the model (validation sample). This model has been used to estimate the probability of an Unplanned Return Visit rate within 72 hours. For its construction, all the variables that presented a $\mathrm{p}$-value of $<0.10$ in the univariate study were taken into account. The odds ratio and its $95 \%$ confidence interval from the coefficients of the definitive model were also calculated. Hosmer and Lemeshow (HL) goodness of fit test was performed to validate the test. Lastly, the Nagelkerke R2 value was used to estimate the proportion of variability.

Discrimination and prediction accuracy was assessed by ordinal area under the curve (AUC) of receiver operating characteristics (ROC) curve calculation. AUC ranges from 
Table 1. Annual ED Census of a Tertiary Private Hospital in Philippines (2017)

\begin{tabular}{|c|c|c|c|c|c|c|c|c|c|}
\hline \multirow{2}{*}{ Month } & \multicolumn{3}{|c|}{ Emergent } & \multicolumn{3}{|c|}{ Urgent } & \multirow{2}{*}{$\begin{array}{c}\text { Non Urgent } \\
\text { Total n (\%) }\end{array}$} & \multirow{2}{*}{ Total } & \multirow{2}{*}{$\begin{array}{c}\text { Pediatric } \\
\text { cases }\end{array}$} \\
\hline & Non-trauma ${ }^{1}$ & Trauma ${ }^{2}$ & Total n (\%) & Non-trauma $^{3}$ & Trauma $^{4}$ & Total n (\%) & & & \\
\hline Jan & 117 & 7 & $124(1.5)$ & 4327 & 632 & 4959 (58.1) & $3447(40.4)$ & 8530 & 30.7 \\
\hline Feb & 94 & 6 & $100(1.4)$ & 3619 & 601 & $4220(60.1)$ & 2703 (38.5) & 7023 & 31.2 \\
\hline Mar & 27 & 4 & 31 (1.1) & 1423 & 195 & $1618(59.8)$ & 1057 (39.1) & 2706 & 46.4 \\
\hline Apr & 116 & 10 & $126(2.2)$ & 2883 & 463 & $3346(59.2)$ & 2178 (38.5) & 5650 & 25.2 \\
\hline May & 101 & 5 & 106 (1.8) & 3057 & 503 & $3560(60.9)$ & 2181 (37.3) & 5847 & 23.9 \\
\hline Jun & 129 & 5 & $134(2.2)$ & 3179 & 528 & 3707 (59.6) & 2379 (38.2) & 6220 & 24.4 \\
\hline Jul & 105 & 3 & $108(1.7)$ & 3387 & 488 & 3875 (59.8) & 2492 (38.5) & 6475 & 30.4 \\
\hline Aug & 101 & 3 & 104 (1.6) & 3326 & 461 & 3787 (57.8) & $2659(40.6)$ & 6550 & 30.3 \\
\hline Sep & 103 & 6 & 109 (1.7) & 2960 & 500 & $3460(55.5)$ & $2663(42.7)$ & 6232 & 28.2 \\
\hline Oct & 98 & 4 & 102 (1.7) & 3109 & 430 & 3539 (58.0) & 2465 (40.4) & 6106 & 33.9 \\
\hline Nov & 120 & 1 & $121(1.7)$ & 3604 & 461 & 4065 (57.4) & $2896(40.9)$ & 7082 & 28.9 \\
\hline Dec & 52 & 3 & $55(1.5)$ & 1871 & 238 & 2109 (55.6) & $1627(42.9)$ & 3791 & 34.0 \\
\hline Total & 1163 & 57 & $1220(1.7)$ & 36745 & 5500 & $42245(58.5)$ & $28747(39.8)$ & 72212 & \\
\hline
\end{tabular}

${ }^{1}$ Emergent Non-Trauma - Medical life-threatening cases requiring immediate resuscitation

${ }^{2}$ Emergent Trauma - surgical life-threatening cases requiring immediate resuscitation

${ }^{3}$ Urgent Non-Trauma - Cases with significant medical problems that could become life-threatening

${ }^{4}$ Urgent Trauma - Cases with significant surgical problems that could become life-threatening

below 0.5 are considered non-informative and near 1.0 as perfect prediction models. A p-value of $<0.05$ was deemed to be significant. The statistical analysis was performed with the SPSS package (Version 25.0, Armonk, NY: IBM Corp) and the software R.

\section{RESULTS}

In 2017, a total of 72,212 ED consultations were recorded for this hospital, with more than half (58.5\%) triaged as Urgent cases, while more than 1/3 (39.8\%) were triaged as non-urgent. Table 1 depicts the Annual Census with an average monthly consultation of 6018, while Table 2 shows the Percentage rate of URVs per month stratified in 24, 48, and 72 hours. Around $10 \%$ of the ED cases were identified as "For Registration," indicating patients that were treated at the ED but missed the registration process, which could not be retrieved.

The rate of $2.67 \%$ of the 72 -hour URV covers the entire URV from the ED index discharge regardless of their connection on the initial and succeeding chief complaints. The study also includes URVs with multiple readmissions during the 72-hour ED index visit. However, it excludes patients with procedures requiring several ED visits. Moreover, we were unable to track the 72-hour URV of patients who initially sought consult at our ED that were readmitted to other ED facilities.

About $38 \%$ of our ED patients are young professionals within the age range of 18-40 years old and paid through a third-party payer represented as Health Maintenance Organizations (HMOs). Currently, $70 \%$ of the patients and their dependents were financed through a third-party payer. The agreement between the Hospital and the thirdparty payers has made ED conducive to providing 24/7
Table 2. Monthly Percentage Rates of 72 hours Unplanned Return Visits Rate after ED index discharge of a Tertiary Private Hospital in the Philippines (2017)

\begin{tabular}{|c|c|c|c|c|c|c|c|c|}
\hline \multirow{2}{*}{ Months } & \multicolumn{2}{|c|}{24 hours } & \multicolumn{2}{|c|}{48 hours } & \multicolumn{2}{|c|}{72 hours } & \multirow{2}{*}{ Total } & \multirow{2}{*}{$\begin{array}{l}\text { URV } \\
\text { (\%) }\end{array}$} \\
\hline & $\mathbf{n}$ & $\%$ & $n$ & $\%$ & $\mathrm{n}$ & $\%$ & & \\
\hline Jan & 121 & 43.2 & 99 & 35.4 & 60 & 21.4 & 280 & 3.28 \\
\hline Feb & 85 & 41.5 & 72 & 35.1 & 48 & 23.4 & 205 & 2.92 \\
\hline Mar & 19 & 38.0 & 17 & 34.0 & 14 & 28.0 & 50 & 1.85 \\
\hline Apr & 43 & 32.3 & 41 & 30.8 & 49 & 36.8 & 133 & 2.35 \\
\hline May & 58 & 39.2 & 52 & 35.1 & 38 & 25.7 & 148 & 2.53 \\
\hline Jun & 57 & 37.5 & 52 & 34.2 & 43 & 28.3 & 152 & 2.44 \\
\hline Jul & 43 & 27.6 & 70 & 44.9 & 43 & 27.6 & 156 & 2.41 \\
\hline Aug & 77 & 44.5 & 45 & 26.0 & 51 & 29.5 & 173 & 2.64 \\
\hline Sep & 69 & 45.7 & 45 & 29.8 & 37 & 24.5 & 151 & 2.42 \\
\hline Oct & 63 & 40.1 & 51 & 32.5 & 43 & 27.4 & 157 & 2.57 \\
\hline Nov & 63 & 31.7 & 81 & 40.7 & 55 & 27.6 & 199 & 2.81 \\
\hline Dec & 51 & 40.8 & 34 & 27.2 & 40 & 32.0 & 125 & 3.30 \\
\hline Average & 62.4 & 38.8 & 54.9 & 34.2 & 43.4 & 27.0 & 160.75 & 2.67 \\
\hline
\end{tabular}

access regardless of the case severity and observing fewer requirements compared with the primary care access counterpart, which has more restrictions on schedules and regulations.

Third-party payers were the preferred payment method of $70 \%$ of our ED population with significantly higher ( $\mathrm{p}<.0001$ ) 72-hour URVs compared with Out of Pocket payers (OOP), as shown in Figure 1.

Around one third of our ED patients were classified as pediatric (within 0 to 18 years old). Pediatric patients have significantly higher ( $\mathrm{p}<.0001$ ) 72-hour URVs ED index visit compared with adults occurring on the first 24 hours, as illustrated in Figures 1 and 2, and triage categories in Figure 1. 
Table 3. Summary results of factors related with 72-hour URVs after ED index discharge of a Tertiary Private Hospital in the Philippines, 2017

\begin{tabular}{|c|c|c|c|c|c|}
\hline Variables & $\mathrm{B}^{1}$ & Sig $^{2}$ & $\mathrm{OR}^{3}$ & \multicolumn{2}{|c|}{$95 \% \mathrm{Cl}^{4}$} \\
\hline \multicolumn{6}{|l|}{ Payment Options } \\
\hline Third party payer & .32 & .000 & 1.37 & 1.18 & 1.59 \\
\hline \multicolumn{6}{|l|}{ Age Category } \\
\hline Pediatrics & 0.95 & .0001 & 2.58 & 2.30 & 2.90 \\
\hline \multicolumn{6}{|l|}{ Service } \\
\hline Urgent & 0.25 & .0001 & 1.29 & 1.14 & 1.45 \\
\hline \multicolumn{6}{|l|}{ Month } \\
\hline January & 0.88 & .0001 & 2.41 & 1.62 & 3.58 \\
\hline February & 0.73 & .0001 & 2.07 & 1.38 & 3.11 \\
\hline March & \multicolumn{5}{|c|}{ Point of Reference } \\
\hline April & 0.58 & .007 & 1.79 & 1.17 & 2.75 \\
\hline May & 0.73 & .001 & 2.07 & 1.36 & 3.15 \\
\hline June & 0.51 & .018 & 1.67 & 1.09 & 2.56 \\
\hline July & 0.55 & .009 & 1.74 & 1.15 & 2.65 \\
\hline August & 0.64 & .003 & 1.89 & 1.25 & 2.86 \\
\hline September & 0.59 & .006 & 1.80 & 1.18 & 2.74 \\
\hline October & 0.49 & .025 & 1.62 & 1.06 & 2.48 \\
\hline November & 0.76 & .0001 & 2.14 & 1.43 & 3.22 \\
\hline December & 0.83 & .0001 & 2.29 & 1.49 & 3.52 \\
\hline Length of Stay & -.04 & .001 & .96 & .93 & .98 \\
\hline $\begin{array}{l}1 \text { Correlation coefficie } \\
2 \text { Significance probabi } \\
3 \text { Odds ratio } \\
{ }_{4}^{4} \text { Confidence interval }\end{array}$ & & & & & \\
\hline
\end{tabular}

Significant URV s occurrences were shown on months of January ( $p<.0001)$, February ( $\mathrm{p}<.0001)$, November $(\mathrm{p}<0001)$, and December $(p<.0001)$. Figure 2 shows the pediatric patients' impact by month where the URVs occur while Table 3 depicts the summary of variables affecting 72-hour URVs.

The p-value associated with the HL goodness of fit test was 0.358 , and the Nagelkerke R2 value was 0.035 .
The adjusted model affords an area under the ROC curve of 0.645 (95\% CI: $0.63-0.66$ ). A cut-off point of 0.025 provides a sensitivity of $58.5 \%$ and specificity of $64.1 \%$. The positive predictive value was set at $4.28 \%$ (the prevalence considered is $2.67 \%$ ) and the negative predictive value at $98.25 \%$. This cut-off point allows us to classify proportions of similar patients in the validation sample, with an area under the ROC curve of 0.639 (95\% CI: 0.62-0.66) (Figure 3).

\section{DISCUSSION}

Globally, measurement of URV within 72 hours after ED index discharge has been a practice, and our institution showed a rate of $2.67 \%$ in 2017 , comparable with international standards. ${ }^{5}$ Nevertheless, the empiric basis for this metric should still be substantiated. ${ }^{9-11}$ Certain studies would contest the appropriateness of 72-hour URVs as a quality indicator since it can reflect the underlying overall social and health care services. ${ }^{1,9-11}$

URVs are influenced by Payment Options (third-party payers have a $37 \%$ more risk for URV compared with OOP), Age (Pediatrics has a $158 \%$ risk for URV compared with Adults), Triage Category (Patients triaged as urgent cases have a $29 \%$ risk compared with other categories such as not urgent or emergent) and finally for the month of the year (Patients who seek consult at the ED within November to February have a $100 \%$ risk of URVs in reference with the month of March).

Results revealed that 72-hour URVs are higher with ED consultations paying through a third-party payer compared with OOP consistent with Medicaid and Medicare studies. ${ }^{9-11}$ Findings explained the association of URVs with insurance is due to the dependence with the insurance provider and the lack of availability for primary care after ED discharge. ${ }^{10}$ The recent local study states

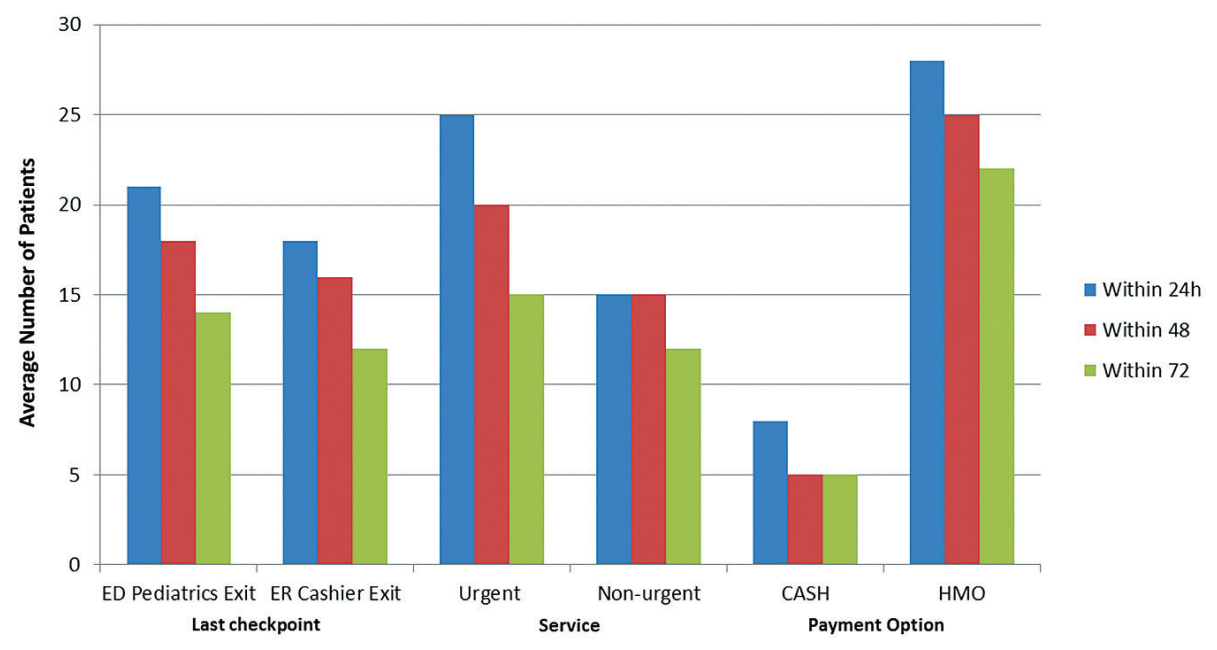

Figure 1. Payment Options, Last checkpoint, and Service (Triage Level), of ED patients with URVs within 72 hours of a Tertiary Private Hospital in the Philippines, 2017. 


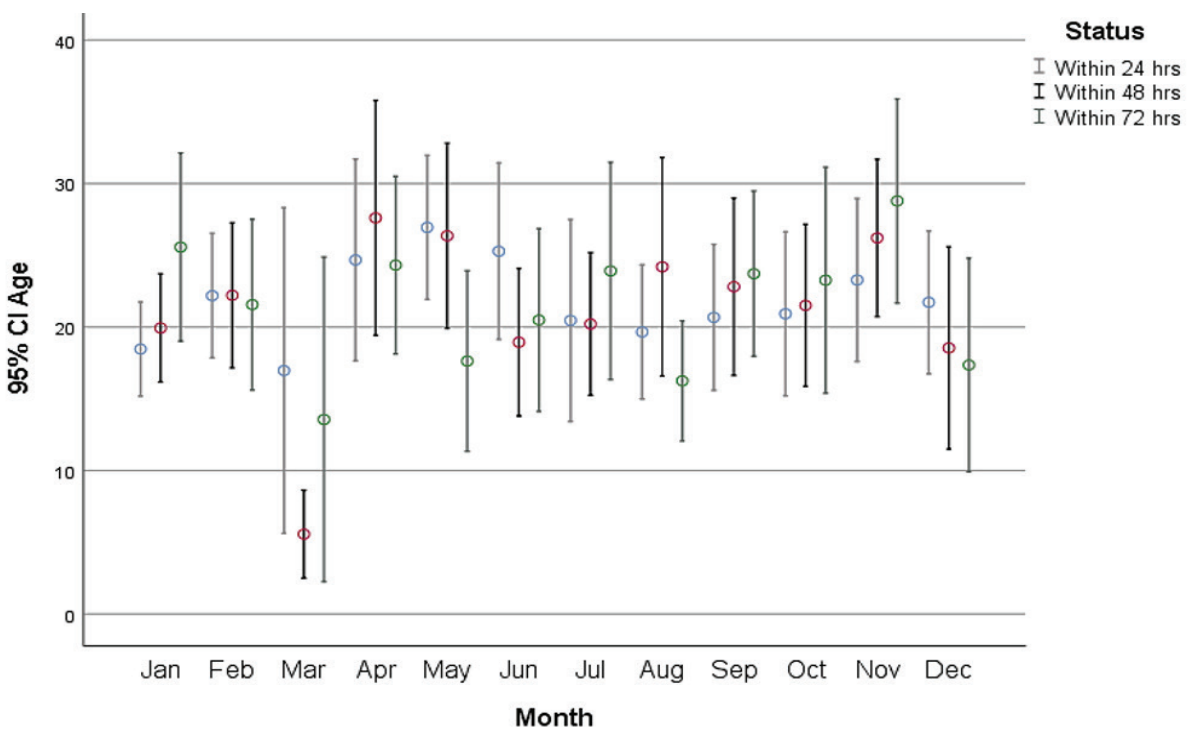

Figure 2. 72 URVs in relation with Age and Month of ED Consultation of a Tertiary Private Hospital in the Philippines, 2017.

that the hospital caters to $70 \%$ young professional patients through a third party payer provided by their respective Business Processing Outsource (BPO) companies operating $24 / 7$ located near the hospital making it accessible. ${ }^{12}$

In a comparative study of adults and pediatrics, $1 / 3$ of the unplanned return visits were pediatrics with a $12 \%$ hospital admission rate associated with an age younger than ten and a chief complaint of fever or upper respiratory tract infections or chronic health cases. ${ }^{13-14}$ A theory that explains the URVs for children was attributed to the parent's reservations on the diagnosis given during the index visit hence resulting in return for re-evaluation. ${ }^{13}$

A list of recommendations was emphasized on the following by giving (a) more targeted advice, (b) a realistic time of recovery and (c) a sustainable follow up on primary

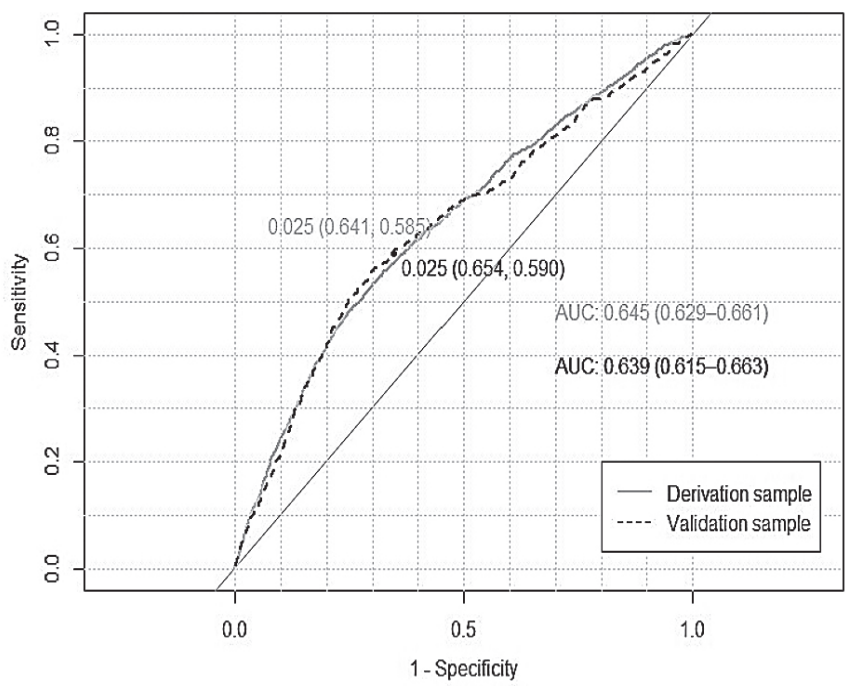

Figure 3. ROC curves for the derivation and validation samples. care to minimize URVs for children presenting with the same condition and severity. ${ }^{15}$

This study discovered significant unplanned return visits on months of January, February, November, and December of 2017 which were also reported in a few studies. ${ }^{16-18}$ Literature using time series data reported that URVs are associated with days of the week, year of the month, and public holidays. ${ }^{18}$ This can explain the increased URVs in our local setting due to major festivities, extended holidays, class suspensions, thereby making doctor's clinics and primary healthcare services unavailable, making ED as a default area for consultations regardless of case severity.

Likewise, this study indicated a strong relationship between URVs and shorter LOS during the ED index visit, which should be investigated since this can be a reflection of an incomplete treatment brought about by strict enforcement of a not more than 4-hour LOS hospital policy in the ED. Traditionally, ED operates based on efficiency which is often measured in LOS since a higher LOS generally contributes to overcrowding, patient's satisfaction, perceptions of care compromise, Left Without Being Seen and direct costs which are all quality measures. ${ }^{19-22}$ However, one of the assumed underlying assumptions of URVs can be due to a premature discharge following the index ED visits. ${ }^{22}$ Due to scarcity of literature, studies support that URV patients stay longer compared with their ED index visit. ${ }^{23-24}$

In another study, URVs are also associated with forprofit hospitals and teaching facilities, which are both correct in this case. ${ }^{10}$ Historically, hospitals for profit rely heavily on private patient payer mix. ${ }^{10}$ With the surge of the third-party payer composing $70-75 \%$ of the patients; healthcare has become more accessible and convenient.

The predictive model which was used that was subsequently supported by the ROC has a beneficial 
application in the Philippine setting at the different levels ranging from the micro-level per hospital (i.e., planning by the ED Department Head, Coordinators, and Managers) to the macro level (i.e., planning by the Local Government Units, Regional Chapters and Department of Health). This will enable us to generate a more substantial result concerning the 72-hour URVs after the ED index visit.

The validity of the 72-hour URVs should also be evaluated. Certain studies contest the underlying principle as a quality indicator. However, its relevance can be valuable in the determination of high-risk groups such as elderly and chronic cases. Nevertheless, evaluation of outcomes of 72-hour URVs, which turned out to be an actual admission to a definite care area or as a sentinel event, should be reported or who ended up as mortality.

\section{Acknowledgment}

To our dear friend and mentor, Dr. Joan Manuel Salmeron (1950-2011) of Hospital Clínico de Barcelona, Spain, we will be forever grateful for your generosity in sharing your expertise and humanity. We hope to continue your legacy in the field of emergency management and operations.

\section{Statement of Authorship}

All authors have approved the final version submitted.

\section{Author Disclosure}

All authors declared no conflicts of interest.

\section{Funding Source}

This work is supported by the Ministry of Economy, Industry, and Competitiveness of Spain [MTM201783850-P] to Professor J.V. Segura-Heras; and the Clinical Translational Research Institute, The Medical City under their Intramural Grant Funding for 2017-2018 [2017-001].

\section{REFERENCES}

1. Pham JC, Kirsch TD, Hill PM, DeRuggerio K, Hoffmann B. Seventy-two-hour returns may not be a good indicator of safety in the emergency department: a national study. Acad Emerg Med. 2011 Apr; 18(4):390-7. doi: 10.1111/j.1553-2712.2011.01042.x.

2. Imsuwan, I. Characteristics of unscheduled emergency department return visit patients within 48 hours in Thammasat University Hospital. J Med Assoc Thai. 2011 Dec; 94 Suppl 7:S73-80.

3. Pierce JM, Kellerman AL, Oster C. "Bounces": an analysis of shortterm return visits to a public hospital emergency department. Ann Emerg Med. 1990 Jul; 19(7):752 -7. doi: 10.1016/S0196-0644(05) 81698-1.

4. Nunez S, Hexdall A, Aguirre-Jaime A. Unscheduled returns to the emergency department: an outcome of medical errors? Qual Saf Health Care. 2006 Apr; 15(2):102-8. doi: 10.1136/qshc.2005.016618.

5. The College of Emergency Medicine. Emergency Department Clinical Quality Indicators: - A CEM guide to implementation [Internet]. Available from: www.collemergencymed.ac.uk.

6. Heyworth J. Emergency medicine-quality indicators: the United Kingdom perspective. Acad Emerg Med. 2011 Dec;18(12):1239-41. doi: 10.1111/j.1553-2712.2011.01223.x.
7. Ko M, Lee Y, Chen C, Chou P, Chu D. Incidence of and predictors for early return visits to the emergency department: a population-based survey. Medicine (Baltimore). 2015 Oct;94(43):e1770. doi: 10.1097/ MD.0000000000001770.

8. Kirby SE, Dennis SM, Jayasinghe UW, Harris MF. Patient-related factors in frequent readmissions: the influence of condition, access to services, and patient choice. BMC Health Serv Res. 2010 Jul; 10:216. doi:10.1186/1472-6963-10-216.

9. Rising KL, Victor TW, Hollander JE, Carr BG. Patient returns to the emergency department: the time-to-return curve. Acad Emerg Med. 2014 Aug; 21(8):864-71. doi: 10.1111/acem.12442. Epub 2014 Aug 24.

10. Gabayan GZ, Asch SM, Hsia RY, Zingmond D, Liang LJ, Han W. Factors associated with short-term bounce-back admissions after emergency department discharge. Ann Emerg Med. 2013 Aug; 62(2):136-44.e1. doi: 10.1016/j.annemergmed.2013.01.017.

11. Hu YH, Tai CT, Chen SC, Lee HW, Sung SF. Predicting return visits to the emergency department for pediatric patients: Applying supervised learning techniques to the Taiwan National Health Insurance Research Database. Comput Methods Programs Biomed. 2017 Jun; 144:105-12. doi:10.1016/j.cmpb.2017.03.022..

12. Jimenez LD, Manzanera RL, Mira JJ, Navarro IM, Wong JQ. A descriptive study on the factors affecting the length of stay in the emergency department of a tertiary private hospital in the Philippines. Acta Med Philipp. 2018 Dec; 52(6):519-26.

13. Cho CS, Shapiro DJ, Cabana MD, Maselli JH, Hersh AL. A national depiction of children with return visits to the emergency department within 72 hours, 2001-2007. Pediatr Emerg Care. 2012 Jul; 28(7): 606-10. doi: 10.1097/pec.0b013e31825cf7cf.

14. Verelst S, Pierloot S, Desruelles D, Gillet J, Bergs J. Short-term unscheduled return visits of adult patients to the emergency department. J Emerg Med. 2014 Aug; 47(2):131-9. doi: 10.1016/ j.jemermed.2014.01.016

15. $\mathrm{Ng} \mathrm{CP}$, Chung $\mathrm{CH}$. An Analysis of Unscheduled Return Visits to the Accident and Emergency Department of a General Public Hospital. Hong Kong J Emerg Med. 2003 Jul; 10(3):153-61. doi: 10.1177/102490790301000304.

16. 劉彥芳, 醫務管理學系碩士. The important factors unplanned return visit in emergency patients, Taiwan, Australia: 中國醫藥大. 學 2011.

17. Sun Y, Heng BH, Tay SY, Tan KB. Unplanned 3-day re-attendance rate at Emergency Department (ED) and hospital's bed occupancy rate (BOR). Int J Emerg Med. 2015 Dec; 8(1):82. doi: 10.1186/s12245015-0082-3.

18. Kirby SE, Dennis SM, Jayasinghe UW, Harris MF. Unplanned return visits to emergency in a regional hospital. Aust Health Rev. 2012 Aug; 36(3):336-41. doi: 10.1071/AH11067.

19. Mowen JC, Licata JW, McPhail J. Waiting in the emergency room: how to improve patient satisfaction. J Health Care Mark. 1993 Summer; 13(2):26-33.

20. Pines JM, Garson C, Baxt WG, Rhodes KV, Shofer FS, Hollander JE. ED crowding is associated with variable perceptions of care compromise. Acad Emerg Med. 2007 Dec;14(12):1176-81.

21. Schumacher JG, Deimling GT, Meldon S, Woolard B. Older adults in the emergency department: predicting physicians' burden levels. J Emerg Med. 2006 May;30(4):455-60. doi: 10.1016/ j.jemermed.2005.07.008.

22. Pines JM, Batt RJ, Hilton JA, Terweish C. The financial consequences of lost demand and reducing boarding in hospital emergency departments. Ann Emerg Med. 2011 Oct; 58(4):331-40. doi: 10.1016/j.annemergmed.2011.03.004.

23. Wang K, Chaou C, Liu P, Chien C, Lee C. Factors Affecting Unscheduled Return Visits to the Emergency Department among Minor Head Injury Patients. BioMed Res Int. 2017; 2017:8963102. doi:10.1155/2017/8963102.

24. Baer RB, Pasternack JS, Zwemer FL. Recently discharged inpatients as a source of emergency department overcrowding. Acad Emerg Med. 2001 Nov; 8(11):1091-14. doi:10.1111/j.1553-2712.2001. tb01121.x. 